\title{
The effectiveness of sexual harassment policies and procedures at higher education institutions in South Africa
}

\author{
Authors: \\ Pierre Joubert ${ }^{1}$ \\ Christo van Wyk ${ }^{2}$ \\ Sebastiaan Rothmann ${ }^{2}$ \\ Affiliations: \\ 'Department Human \\ Resource Management, \\ Vaal University of \\ Technology, South Africa \\ ${ }^{2}$ School of Behavioural \\ Sciences, North-West \\ University, South Africa \\ Correspondence to: \\ Pierre Joubert \\ Email: \\ pierrej@vut.ac.za \\ Postal address: \\ Private Bag X021, \\ Vanderbijlpark 1900, \\ South Africa \\ Dates: \\ Received: 28 June 2010 \\ Accepted: 19 Oct. 2010 \\ Published: 25 Feb. 2011 \\ How to cite this article: \\ Joubert, P., Van Wyk, C., \\ \& Rothmann S. (2011). \\ The effectiveness of \\ sexual harassment \\ policies and procedures \\ at higher education \\ institutions in South Africa. \\ SA Journal of Human \\ Resource Management/ \\ SA Tydskrif vir \\ Menslikehulpbronbestuur, \\ 9(1), Art. \#310, 10 pages. \\ doi:10.4102/sajhrm. \\ v9i1.310
}

Orientation: Sexual harassment policies are generally in place in higher education institutions without any indication of its effectiveness as determined by the awareness of the policy.

Research purpose: The aim of this study was to investigate the awareness levels of academic staff members at higher education institutions in South Africa of sexual harassment policies and procedures in their institutions.

Motivation for the study: A number of high profile court cases emphasised the need for effective policies to reduce the incidence of sexual harassment complaints.

Research design, approach and method: A cross-sectional survey design was conducted amongst 161 academic staff members, representing 10 higher education institutions in South Africa. The measuring instrument that was used is the Sexual Harassment Questionnaire (SHQ) that was developed specifically for this study.

Main findings: The results showed that despite indications that sexual harassment policies do exist and that they are regarded as effective tools in addressing sexual harassment, the implementation of such policies is not effective and few academic staff members received training and/or guidance on the utilisation of the policy. Significant correlation coefficients were found between the elements of an effective policy and between population group and some of the elements.

Practical/managerial implications: Employers across the board should regularly conduct an audit to determine the level of awareness of sexual harassment policies and procedures and plan interventions.

Contribution/value-add: No other study in South Africa attempted to measure the awareness levels of academics and its impact on the management of sexual harassment.

\section{Introduction}

Employers have much to lose if they fail to create and maintain a work environment that is free of sexual harassment (Pearce \& DiLullo, 2001). Failure to guarantee such an environment will have adverse consequences for organisations and will manifest in personal harm to victims and negatively affect their productivity, as well as in cost and possible legal implications for employers (Bennet, 2002; Grobler, Erasmus \& Kölkenbeck-Ruh, 2003). The statement by Pearce and DiLullo (2001) holds a serious warning for employers and refers to the issue of vicarious liability. This liability is rooted in the generally accepted principle that an employer has a duty of care to ensure that the workplace is an environment free from sexual harassment. To achieve this, an employer is expected to appropriately communicate to employees that sexual harassment is not tolerated, to educate and counsel employees regarding workplace policies on sexual harassment and to take decisive steps when incidents of sexual harassment are brought to employees' attention (Rycroft, Le Roux \& Orleyn, 2005). Failure on the part of an employer to meet these expectations may result in the employer being found vicariously liable for the sexual harassment of an employee. The case of Media 24 Limited and Samuels v Grobler (2005) 16(4) SALLR (SCA) is a case in point where the employer had to pay substantial damages to its former employee as a result of the failure to adequately address her complaints of sexual harassment.

The Employment Equity Act no. 55 of 1998 (South Africa, 1998) states that an employer is not liable for the conduct of an employee if the employer is able to prove that everything reasonably practicable was done to ensure that its employees do not contravene the Act by committing 
sexual harassment. What is regarded as reasonable steps by an employer to prevent an employee from being sexually harassed is provided in the guiding principles of the 2005 Amended Code of Good Practice on the Handling of Sexual Harassment Cases in the Workplace (Labour Relations Act no 66 of 1995; South Africa, 1995). For the purpose of this study, the definition provided by the 2005 Amended Code of Good Practice on the Handling of Sexual Harassment Cases, which was issued in terms of the Labour Relations Act no. 66 of 1995 (South Africa, 1995) is used as the definition of sexual harassment. According to this Code, sexual harassment is defined as follows:

Sexual harassment is unwanted conduct of a sexual nature that violates the rights of an employee and constitutes a barrier to equity in the workplace, taking into account all of the following factors: a) whether the harassment is on the prohibited grounds of sex and/or gender and/or sexual orientation; b) whether the sexual conduct was unwelcome; $\mathrm{c}$ ) the nature and extent of the sexual conduct, and d) the impact of the sexual conduct on the employee.

(2005 Amended Code of Good Practice on the Handling of Sexual Harassment Cases)

In all probability, this definition will be used by courts and councils when a case of sexual harassment is arbitrated and this will aid employers in providing an objective and 'legal' definition of sexual harassment.

It is accepted that most organisations and especially most institutions of higher education in South Africa have sexual harassment policies in place. A study conducted by Wilken and Badenhorst (2003) confirms this but also points out serious deficiencies in the content and especially the implementation of these policies. No research has been done in South Africa regarding the effectiveness of sexual harassment policies in higher education institutions that the researcher is aware of. According to Gouws and Kritzinger (2007) and Wilken and Badenhorst (2003), most higher education institutions in South Africa have introduced sexual harassment policies. However, little evidence exists on the effectiveness of these policies in terms of the requirements for an effective policy. This study will contribute to the body of knowledge regarding the effectiveness of sexual harassment policies and the success of their implementation.

The objectives of this study were to:

- determine the level of awareness of sexual harassment policies

- determine the perception of the effectiveness of sexual harassment policies amongst academic staff at higher education institutions in South Africa.

\section{Sexual harassment}

An important aspect of vicarious liability is the reasoning that an employer can be held responsible for failing to prevent one of its employees from creating an intolerable situation for another employee. Employers are thus held liable not for what they did but rather for what they did not do in terms of prevention (pro-active) and investigation (reactive) of sexual harassment. This emphasises the need for an effective sexual harassment policy (SHP). In order to balance the relationship between employer and employee, a duty rests in the first instance on the employee to inform the employer immediately after the harassment occurs as an employer cannot be held liable under the Employment Equity Act no. 55 of 1998 (South Africa, 1998) for incidents of which it was ignorant. Whilst cognisance needs to be taken of the reasons why employees do not report all incidents of sexual harassment, it is most unfair to expect from an employer to take action against a harasser if the incident of harassment is not reported to the employer. It seems as if the best strategy to prevent claims of vicarious liability against an employer is to discourage employees from indulging in sexual harassment and to put procedures in place for the resolution of incidents that may yet occur (Anon, 2004; Grogan, 2004).

An employer may also be relieved of liability if it can prove that it took reasonable steps to prohibit and remedy sexual harassment and if it can show that the employee unreasonably failed to use the corrective opportunities made available by the employer (Laabs, 1998). Consensus exists in the literature that the best form of defence for an employer is the implementation and maintenance of an effective policy on sexual harassment (Aalberts \& Seidman, 1996; Bennet, 2002; Caudron, 1995; Hayter, 1996; Kastl \& Kleiner, 2001; Laabs, 1998; Moore, Gatlin-Watts \& Cangelosi, 1998; Owens, Gomes \& Morgan, 2004; Peirce, Rosen \& Hiller, 1997).

The mere existence of a comprehensive policy will not necessarily succeed in managing sexual harassment successfully. A policy needs to be effective and effectiveness is determined by a number of factors. According to Wilken and Badenhorst (2003), the policy should be clearly worded, readily displayed at strategic points and regularly evaluated to ensure that it remains effective. They are supported by Aalberts and Seideman (1996) who stress that the workplace is a changing environment and because the expectations of employees and the nature of their work may change, the policy must be monitored by management. To ensure the effectiveness of sexual harassment policies and training programmes, Grobler, Erasmus and KölkenbeckRuh (2003) recommended that an organisation develop programmes as a preventative measure and not just as a means of crisis management. The dimensions of realism and appropriateness are added to by Timmerman and Bajema (2000), who stress the need for sexual harassment policies to address the organisational culture of the organisation. The sexual harassment policy statement should be clear, emphatic and easily understood. It should be free of confusing legal terminology that may seem impressive but does not inform employees of their expected behaviour (Pearce \& DiLullo, 2001).

Caudron (1995) reports on some of the negative effects of programmes designed to prevent sexual harassment. For example, in some companies the workforce were polarised, making men feel defensive and women victimised by the programmes that were supposed to raise awareness of 
sexual behaviour that is inappropriate in the workplace. In addition, these programmes raised fear and anxiety, inhibiting spontaneity and communication, and increased the distance between men and women. After analysing these problems, it was possible to conclude that the way in which these programmes were implemented may have caused these problems, especially when the approach to sexual harassment was only one of men who harass women. A unilateral single-gender biased approach will lead to conflict, which stresses the importance of having an objective policy applied with sensitivity by sufficiently qualified and trained people.

According to Stockdale (1996), there is no perfect policy or procedure for dealing with sexual harassment. Three reasons are provided for this statement. Firstly, it is nearly impossible to design a system that will satisfy all its users. Some complainants may feel more injured or unfairly treated, especially if the only evidence is one person's word against another. Secondly, the differences between organisations in terms of their missions, rules, traditions and location make it very difficult to have a perfect policy. The third reason refers to the differences between people regarding what constitutes a good policy. Stockdale (1996) distinguished between two groups, namely those who believe in an interest-based approach and those who prefer a rights-based approach. The first group will accept a direct approach, mediation or avoidance as a means of handling the incident whilst the second group will only accept an investigation, adjudication and severe disciplinary action. A similar argument can be raised regarding the specific or general nature of sexual harassment policies and procedures. Arguments for a policy solely about sexual harassment are based on the differences in the origin, manifestation and effect of each kind of harassment, the sense of urgency that it conveys about one particular kind of harassment and the improvement in understanding if it (type of harassment) is narrowly defined. General policies may also be described as too vague. On the other hand, general policies may be preferred because they:

- are used by more complainants and are more widely understood

- may be seen as fairer as they protect everybody and not just a specific group

- provide for more choices for individuals

- may avoid certain semantic disagreements (sexual and/ or racial harassment).

These arguments are provided by Rowe (1996) who also stressed that whatever type of policy is used all policies should define harassment, provide examples of discrimination, describe management responsibilities and list the options available for dealing with harassment.

\section{Implementation of a sexual harassment policy}

A number of authors concur that the mere presence of a policy does not ensure its effectiveness (Laabs, 1998; Orlov \& Roumell, 1999; Owens, Gomes \& Morgan, 2004; Paludi, 1996). A policy has to be effectively implemented in order to have value and to avoid becoming another well-formulated, impressive sounding document compiled by consultants and filed by the human resource department. The following guidelines are suggested for the effective implementation of a sexual harassment policy (Finnemore \& Van Rensburg, 2002; Laabs, 1998; Orlov \& Roumell, 1999; Owens, Gomes \& Morgan, 2004; Paludi, 1996; Retief, 2000):

- Create awareness by including the policy in as many programmes as possible, such as in orientation, education, training and diversity awareness programmes. This will contribute to the creation of a culture where sexual harassment is not tolerated. Trade unions should be involved in every step of the implementation process.

- Communicate the policy to all employees at every level of the organisation by providing each one with a copy of the policy and keep signatures on file that employees received the policy. This signature may prove vital in an organisation's defence against claims of vicarious liability.

- Conduct regular training sessions or workshops where the content of the policy and the complaints procedure are explained. 'These training sessions should continuously reinforce the conditions that contribute to a harassment-free working environment, and should familiarise or reacquaint each employee with their rights and responsibilities' (Owens, Gomes \& Morgan, 2004).

- Ensure that managers and supervisors are aware of their responsibility for implementing the policy and ensuring compliance.

- Provide specialised training for individuals who were assigned an official role in administering the organisation's complaint procedure.

The following hypothesis is formulated:

Hypothesis: Academic staff members at higher education institutions in South Africa are generally not aware of sexual harassment policies.

\section{Research design Research approach}

A quantitative approach was followed in this study. More specifically, a survey design was used. This design is suitable to explore the opinions of respondents regarding the effectiveness of the sexual harassment policy at their institutions (Bless \& Higson-Smith, 2004).

\section{Research method Research participants}

All 23 higher education institutions in South Africa were invited to participate in the study. Based on their responses, a purposive sample (Maree, 2007) of 10 institutions was used. Academic staff at the following South African higher education institutions participated in the study: Central University of Technology, Fort Hare University, Free State University, Nelson Mandela Metropolitan University, North-West University, Rhodes University, University of 
Johannesburg, University of KwaZulu-Natal, Vaal University of Technology and Walter Sisulu University of Technology. The sample represents 10 of the 23 higher education institutions in South Africa. In their analysis of sexual harassment policies at selected higher education institutions in South Africa, Wilken and Badenhorst (2003) regarded eight universities as sufficiently representative of the current higher education sector in South Africa. This sample contains five traditional universities, two comprehensive universities and three universities of technology. As such, the sample is regarded as representative of the changed landscape of higher education in South Africa.

The biographical characteristics of the study population are presented in Table 1.

Table 1 indicates that $64 \%$ women and $36 \%$ men participated in this study. The majority of participants (33.5\%) fell in the 31-39 age groups and $52.8 \%$ had a master's degree level of education. The majority of the study population (20.5\%) had been employed by their institutions for periods of between five and seven years.

\section{Measuring instrument}

The Sexual Harassment Questionnaire (SHQ) was developed following the literature review, which was conducted in order to ensure the correct identification of the dimensions

TABLE 1: Characteristics of the participants.

\begin{tabular}{|c|c|c|c|}
\hline Item & Category & $f$ & $\%$ \\
\hline \multirow[t]{3}{*}{ Gender } & Male (1) & 58 & 36.0 \\
\hline & Female (2) & 103 & 64.0 \\
\hline & Total & 161 & 100 \\
\hline \multirow[t]{5}{*}{ Population group } & African & 24 & 15.3 \\
\hline & Asian & 8 & 5.1 \\
\hline & Coloured & 6 & 3.8 \\
\hline & White & 119 & 75.8 \\
\hline & Total & 157 & 100 \\
\hline \multirow[t]{4}{*}{ Home Language } & Afrikaans & 76 & 47.2 \\
\hline & English & 66 & 41.0 \\
\hline & African Language & 19 & 11.8 \\
\hline & Total & 161 & 100 \\
\hline \multirow[t]{6}{*}{ Age } & 30 years and younger (1) & 16 & 9.9 \\
\hline & $31-39$ years $(2)$ & 54 & 33.5 \\
\hline & $40-49$ years $(3)$ & 46 & 28.6 \\
\hline & $50-59$ years $(4)$ & 43 & 26.7 \\
\hline & $60-$ and older (6) & 2 & 1.2 \\
\hline & Total & 161 & 99.9 \\
\hline \multirow[t]{5}{*}{ Qualification } & Doctorate (1) & 39 & 24.2 \\
\hline & Master's (2) & 85 & 52.8 \\
\hline & Hons/BTech (3) & 32 & 19.9 \\
\hline & Degree/Diploma (4) & 5 & 3.1 \\
\hline & Total & 161 & 100 \\
\hline \multirow[t]{9}{*}{ Tenure } & Less than 2 years ( 1 ) & 20 & 12.4 \\
\hline & $2-4$ years $(2)$ & 23 & 14.4 \\
\hline & $5-7$ years $(3)$ & 33 & 20.5 \\
\hline & $8-10$ years (4) & 25 & 15.5 \\
\hline & $11-13$ years & 25 & 15.5 \\
\hline & $14-16$ years & 9 & 5.6 \\
\hline & $17-19$ years & 11 & 6.8 \\
\hline & Longer than 20 years (5) & 15 & 9.3 \\
\hline & Total & 161 & 100 \\
\hline
\end{tabular}

f, frequency. of the study and to ensure that the items in the questionnaire were relevant. The questionnaire was circulated amongst colleagues in the field of expertise to obtain feedback on its suitability. This ensured face and content validity. A pilot test was conducted on 22 subjects. A few minor changes were made to the original questionnaire, based on feedback from the respondents. The questionnaire consists of four sections. Section A was designed to obtain biographical information from the respondents. Owing to the sensitive nature of the topic, the questionnaire was completed anonymously and institutions are not identified.

Section $C$ is made up of 15 items designed to determine the level of awareness respondents have regarding the existence and effectiveness of sexual harassment policies, as well as their knowledge of these policies in their respective institutions. These items are part of the constructs of awareness, existence and effectiveness that were identified from the literature study as determinants of an effective policy (Aalberts \& Seidman, 1996; Bennet, 2002; Caudron, 1995; Hayter, 1996; Kastl \& Kleiner, 2001; Laabs, 1998; Moore, Gatlin-Watts \& Cangelosi, 1998; Owens, Gomes \& Morgan, 2004; Peirce, Rosen \& Hiller, 1997). The specific items are reported in Table 2. A 5-point Likert scale was used to assess the level of awareness. Respondents had to indicate if they 'strongly agree with' (1), 'agree with' (2), 'disagree with' (3), 'strongly disagree with' (4) or 'are not sure of' (5) the statements relating to the status of the sexual harassment policy at their institutions.

\section{Research procedure}

The names of the academic staff members were obtained from the official Internet websites of the institutions and a random systematic sample of $10 \%$ of all participating institutions was drawn. The length of the interval was calculated by the ratio $k=N / n$, where $k=$ the length, $N=$ size of the population and $n=$ size of the sample (Bless \& Higson-Smith, 2004). Questionnaires were sent to 710 participants. A response rate of $22.7 \%(n=161)$ was achieved.

The participants represent academic staff on different job levels and range from junior lecturers to professors and deans of faculties. Owing to confidentiality and the sensitivity of the research topic, no individual responses for the participating institutions are reported. The participants are representative of the population because they are in academic positions and are in interaction with the various role players at their respective institutions. This places them in a position to provide information on the perceived incidence of sexual harassment as well as on the awareness and effectiveness of policies and procedures.

\section{Statistical analysis}

The statistical analysis was carried out with the help of the SPSS-program, Version 15 (SPSS, 2007). Cronbach alpha coefficients were used to assess the reliability of the constructs that were measured in this study (Dillon, Madden \& Firtle, 1990). Descriptive statistics (e.g. means and standard 


\begin{tabular}{|c|c|c|c|c|c|c|}
\hline Item & Factor & Strongly agree (\%) & Agree (\%) & Disagree (\%) & Strongly disagree (\%) & Total (\%) \\
\hline $\mathrm{C} 1$ & Policy exists & 37.4 & 60.0 & 1.7 & 0.9 & 100 \\
\hline $\mathrm{C} 2$ & Possession of policy & 13.8 & 17.2 & 46.2 & 22.8 & 100 \\
\hline C3 & Policy explained & 2.0 & 5.9 & 51.6 & 40.5 & 100 \\
\hline C4 & High incidence of harassment & 3.7 & 3.7 & 46.9 & 45.7 & 100 \\
\hline C5 & Aware of contents & 7.9 & 24.3 & 42.1 & 25.7 & 100 \\
\hline C6 & Recognise behaviour & 23.3 & 51.4 & 20.4 & 4.9 & 100 \\
\hline C7 & Training or guidance received & 3.2 & 21.1 & 42.1 & 33.6 & 100 \\
\hline C8 & Steps to report & 10.7 & 24.8 & 45.5 & 19.0 & 100 \\
\hline C9 & Complaints investigated & 20.3 & 42.4 & 16.9 & 20.4 & 100 \\
\hline $\mathrm{C} 10$ & Aware of rights & 20.0 & 37.4 & 30.4 & 12.2 & 100 \\
\hline C11 & Applies to females only & 7.4 & 5.6 & 43.5 & 43.5 & 100 \\
\hline C12 & Effective tool to reduce & 27.8 & 53.4 & 15.8 & 3.0 & 100 \\
\hline C13 & Transgressors punished & 15.2 & 34.8 & 30.4 & 19.6 & 100 \\
\hline C14 & Protects against retaliation & 12.8 & 58.6 & 18.6 & 10.0 & 100 \\
\hline C15 & Low incidence of harassment & 26.9 & 58.2 & 13.4 & 1.5 & 100 \\
\hline
\end{tabular}

deviations) were used. Pearson's product moment correlation coefficients were used to specify the relationship between the variables. In terms of statistical significance, the value was set at a 95\% confidence interval level ( $p \leq 0.05)$ (Neuendorf, 2002). One-way analysis of variance (ANOVA) was used to analyse the variance between independent and dependent variables or factors (Sarantakos, 2006).

\section{Results}

A summary of the frequencies reported by respondents is provided in Table 2.

A frequency analysis of the responses indicates that the overall majority (97.4\%) of respondents agree that a sexual harassment policy exists in their institution. The implementation of the policy however seems to be problematic as very few $(31 \%)$ academic staff members are in possession of a copy of the policy, only $24.3 \%$ received training or guidance in the use of the policy and the policy has been explained to an even smaller number of respondents $(7.9 \%)$. This explains the low frequency of respondents who are aware of the contents of the policy (32.2\%) and who are familiar with the steps to follow when reporting complaints of sexual harassment $(35.5 \%)$. Notwithstanding these indications of ineffective implementation, $81.2 \%$ of respondents believe that a sexual harassment policy is an effective tool to reduce the incidence of sexual harassment. This is supported by the $62.7 \%$ of respondents who believe that complaints of sexual harassment are investigated and the $57.4 \%$ of respondents who are aware of their rights when lodging a complaint. The effectiveness of a sexual harassment policy is illustrated by the $71.5 \%$ of respondents who agreed that the policy protects them against retaliation.

Descriptive statistics of the existence, knowledge and effectiveness of an SHP, as well as the incidence of sexual harassment at higher education institutions in South Africa are reported in Table 3.

The overall Cronbach alpha value obtained for the items in this section is 0.88 , which is higher than the guideline of $\alpha>0.70$. This is an indication of internal consistency and it reflects that the dimensions reliably determine the existence, awareness and effectiveness of sexual harassment policies. The information reflected in Table 4 also indicates that the scores on all of the variables have a normal distribution, with a normal (mesokurtic) peak (Doane \& Seward, 2007).

Practically significant correlation coefficients $(p<0.01)$ of medium effect $(r>0.30)$ exist between population group and knowledge of the policy and existence and effectiveness of sexual harassment policies. The correlation coefficient between population group and the effectiveness of policies is practically significant $(p<0.05)$, with a medium effect $(r>0.30)$ whilst practically significant correlation coefficients $(p<0.05)$ of a large effect $(r>0.50)$ exist between knowledge and existence of the policy, and knowledge and effectiveness of the policy.

Table 5 shows a practically significant correlation coefficient $(p<0.01)$ of a medium to large effect $(r>0.50)$ between the possession and explanation of a SHP and the awareness of the contents, the provision of training or guidance and knowledge of the steps to report an incident of sexual harassment.

The coefficients in Table 6 show a practically significant correlation $(p<0.01)$ of a large effect $(r>0.50)$ between the awareness of rights and the perception that complaints of sexual harassment are investigated. This correlation also exists between the perception that a SHP is an effective tool to reduce the incidence of sexual harassment and that it protects complainants from retaliation by alleged harassers. The perceived incidence level of sexual harassment at higher education institutions was also measured in this section by asking respondents to indicate whether the incidence was

TABLE 3: Descriptive statistics of the measuring instruments.

\begin{tabular}{lcccc}
\hline Scale & Mean & SD & Skewness & Kurtosis \\
\hline Existence of policy & 2.41 & 0.86 & 0.11 & -0.46 \\
Knowledge of policy & 2.62 & 0.62 & -0.17 & 0.11 \\
$\begin{array}{l}\text { Effectiveness of policy } \\
\begin{array}{l}\text { Incidence of sexual } \\
\text { harassment }\end{array}\end{array}$ & 2.85 & 0.56 & -0.24 & 0.66 \\
\hline
\end{tabular}

SD, standard deviation. 
TABLE 4: Correlation coefficients between gender, population group, age, years of service, existence, knowledge and effectiveness of the policy.

\begin{tabular}{|c|c|c|c|c|c|c|c|}
\hline Variables & Gender & $\begin{array}{l}\text { Population } \\
\text { group }\end{array}$ & Age & $\begin{array}{l}\text { Years of } \\
\text { service }\end{array}$ & Existence of policy & $\begin{array}{l}\text { Knowledge of } \\
\text { policy }\end{array}$ & $\begin{array}{l}\text { Effectiveness of } \\
\text { policy }\end{array}$ \\
\hline Gender & - & - & - & - & - & - & - \\
\hline Population group & 0.06 & - & - & - & - & - & - \\
\hline Age & $-0.22 * *$ & 0.10 & - & - & - & - & - \\
\hline Years of service & -0.06 & $0.28 * *$ & $0.49 * *$ & - & - & - & - \\
\hline Existence of policy & -0.04 & 0.08 & -0.01 & -0.12 & - & - & - \\
\hline Knowledge of policy & 0.00 & $0.34 * *$ & 0.11 & 0.10 & $0.60 * *$ & - & - \\
\hline Effectiveness of policy & 0.09 & $0.17^{*}$ & 0.04 & 0.07 & $0.40 * *$ & $0.64 * *$ & - \\
\hline
\end{tabular}

*, correlation is significant at the 0.05 level (2-tailed); ${ }^{* *}$, correlation is significant at the 0.01 level (2-tailed).

high or low at their institutions. A practically significant correlation coefficient of $-0.61(p<0.01)$ was established.

Analyses of variance were performed on various variables with the different demographic groups and the ANOVAs are given below with their interpretations. Table 7 illustrates the effect of gender on the requirements for an effective sexual harassment policy.

Table 7 shows that there is no practically significant effect of gender on the existence, knowledge of and effectiveness of a SHP $(p>0.05)$.

Table 8 reflects the effect of population group on the requirements for an effective sexual harassment policy.

Table 8 shows that there is no practically significant effect of population group on the existence and effectiveness of a SHP $(p>0.05)$. However, it does show a practically significant effect $(F=7.10 ; p>0.05)$ on knowledge of the SHP. Neither age nor years of service were found to have any significant effect on the existence, knowledge of and the effectiveness of a SHP.

\section{Discussion}

The objective of this study was to determine the awareness level academic staff members working at higher education institutions in South Africa have regarding the sexual harassment policies at their institutions. An evaluation of the perceived effectiveness of the policies was also done. Results indicate that despite the indication that sexual harassment policies do exist and are regarded as effective tools to address sexual harassment, the implementation of these policies is not effective and few academic staff receives training or guidance on the utilisation of these policies. Significant correlation coefficients were found between the elements of an effective policy and between population group and some of the elements. The Cronbach alpha value obtained for the items intended to measure the existence, knowledge of and effectiveness of SHP's was 0.88 , which is higher than the guideline of $\alpha>0.70$. Owing to the lack of similar research on this topic or the non-reporting of alpha values (Peirce, Rosen, \& Hiller, 1997), it is not possible to benchmark the Cronbach alpha.

This study indicates that the implementation of a sexual harassment policy at higher education institutions in South Africa is problematic. Only $32 \%$ of the respondents in this study indicated that they are aware of the contents of their institution's sexual harassment policy. A relatively small number of respondents $(24.3 \%)$ have received training or guidance on the policy and this contributed to the low levels of knowledge of the policy. This raises serious questions about the ability of staff to recognise and report harassing behaviour and of line management to effectively deal with complaints of sexual harassment. Because a clear definition of sexual harassment is regarded as a prerequisite for an effective SHP, it is important for the management of higher education institutions to understand what types of behaviour may be perceived by employees as offensive. This study adds to the body of knowledge on perceived sexual harassment and should contribute to the formulation and implementation of effective SHPs. This finding is concomitant with those of Gouws and Kritzinger (2007) who found that only 56\% of heads of academic departments and even less members of the Women's Forum (36\%) at the University of Stellenbosch were informed about the sexual harassment policy.

Peirce, Rosen, \& Hiller (1997) found that more than 40\% of the respondents in their study indicated that they were not aware of the sexual harassment policies or the procedures for reporting complaints of sexual harassment in their organisations. Wilken and Badenhorst (2003) also rated the policies of eight universities in South Africa as failing in terms of education, training and implementation. Although their study did not include any comprehensive university or university of technology (previously referred

TABLE 5: Correlation coefficients between possession, explanation, awareness, training and steps to report.

\begin{tabular}{lcccc}
\hline Variables & Possession & Explanation & $\begin{array}{c}\text { Aware of } \\
\text { contents }\end{array}$ & $\begin{array}{c}\text { Training or } \\
\text { guidance }\end{array}$ \\
\hline Possession & - & - & - & - \\
Explanation & $0.49^{* *}$ & - & - & - \\
Aware of contents & $0.76^{* *}$ & $0.52^{* *}$ & - & - \\
Training/guidance & $0.43^{* *}$ & $0.55^{* *}$ & $0.53^{* *}$ & - \\
Steps to report & $0.63^{* *}$ & $0.49^{* *}$ & $0.75^{* *}$ & $0.55^{* *}$ \\
\hline
\end{tabular}

**, correlation is significant at the 0.01 level (2-tailed).

TABLE 6: Correlation coefficients between investigation, awareness of rights, effective tool and protection.

\begin{tabular}{llll}
\hline Variables & Investigation & Aware of rights & Effective tool \\
\hline Investigation & - & - & - \\
Aware of rights & $0.65^{* *}$ & - & - \\
Effective tool & 0.20 & 0.05 & - \\
Protection & 0.20 & $0.32^{*}$ & $0.52^{* *}$ \\
\hline
\end{tabular}

*, correlation is significant at the 0.05 level (2-tailed); ${ }^{* *}$, correlation is significant at the 0.01 level (2-tailed). 
to as technikons), it is doubtful whether the results would have been different. Consensus seems to exist on the ineffective implementation of sexual harassment policies in higher education institutions and this severely affects the effectiveness of the policies and the protection that the policy is supposed to give to harassers and the harassed.

A comment needs to be made about the $74.6 \%$ of respondents who indicated that they know exactly which behaviour constitutes sexual harassment. This is in contrast to the low number of respondents who are informed about the policy and is an indication that despite the lack of information and training, academic staff members feel that they will be able to recognise offensive behaviour. Questions need to be raised about the basis of this recognition, as respondents represent different cultures, value systems and levels of experience. Their definitions of sexual harassment will therefore be different and subjective and this will complicate the implementation of a uniform policy applicable to all academic staff members, unless institutions subscribe to the definition and guidelines provided in the 2005 Amended Code of Good Practice on the Handling of Sexual Harassment Cases in the Workplace (Labour Relations Act no 66 of 1995; South Africa, 1995). The need for the effective implementation of a generally acceptable policy is once again stressed.

On a positive note, $87 \%$ of respondents disagreed with the statement 'The sexual harassment policy only applies to female workers who are harassed by male workers' (questionnaire item). This item was included to determine if any large-scale misconception about the recipients of unwelcome sexual attention exists (Corr \& Jackson, 2001). The rejection of this statement is an indication of the maturity of the population and the development of a non-sexist society in general. Respondents were also requested to indicate the perceived level of incidence of harassment on their campuses. Of the respondents, $92.6 \%$ rejected the statement that there is a high incidence of harassment by members of staff on their campuses. This correlates significantly with the $85.1 \%$ who indicated that the incidence is low. The apparent absence of sexual harassment amongst academic staff on South African higher education campuses may be ascribed to the low reporting rate of incidents and the confidential nature of complaints (Timmerman \& Bajema, 2000; Whatley \& Wasieleski, 2001). If a staff member is not directly involved in an incident, it will be difficult to have knowledge thereof and to express an opinion on the incidence rate. This study attempted to measure the perceived incidence and the conclusion can be made that it is low.

A significant correlation and effect $(F=7.10 ; p>0.05)$ was found between population group and knowledge of the SHP, with respondents from the White population group having a higher level of knowledge of the policy. This may be explained by the fact that academic staff members of higher education institutions in South Africa were predominantly White and have longer years of service, which would have enabled them to gain knowledge of the policy. The difference in knowledge may also be ascribed to cultural differences and the slow rate of transformation at some institutions of higher learning.

The significant correlation between the possession, explanation, awareness of the contents, training or guidance of a SHP and knowledge of the steps to follow when reporting incidents of sexual harassment is an indication of the importance of providing all staff members with a copy of the SHP. The correlation also suggests that staff members who are in possession of the policy have studied the policy and are, therefore, familiar with the contents and

TABLE 7: Analysis of variance between the existence, knowledge of and effectiveness of a sexual harassment policy and gender.

\begin{tabular}{|c|c|c|c|c|c|c|}
\hline Sexual harassment policy & Effect & Sum of Squares & Degrees of Freedom & Mean Square & $\boldsymbol{F}$ & $p$ \\
\hline \multirow[t]{3}{*}{ Existence of sexual harassment policy } & Between Groups & 0.21 & 1 & 0.21 & 0.28 & 0.60 \\
\hline & Within Groups & 113.68 & 153 & 0.74 & - & - \\
\hline & Total & 113.89 & 154 & - & - & - \\
\hline \multirow[t]{3}{*}{ Knowledge of sexual harassment policy } & Between Groups & 0.00 & 1 & 0.00 & 0.00 & 0.97 \\
\hline & Within Groups & 60.77 & 155 & 0.39 & - & - \\
\hline & Total & 60.77 & 156 & - & - & - \\
\hline \multirow[t]{3}{*}{ Effectiveness of sexual harassment policy } & Between Groups & 0.41 & 1 & 0.41 & 1.30 & 0.26 \\
\hline & Within Groups & 49.96 & 157 & 0.32 & - & - \\
\hline & Total & 50.37 & 158 & - & - & - \\
\hline
\end{tabular}

$F$, indicates the test statistic of difference and is compared with the critical value of $F$ to determine its significance $p$.

TABLE 8: Analysis of variance between the existence, knowledge of and effectiveness of a sexual harassment policy and population group.

\begin{tabular}{|c|c|c|c|c|c|c|}
\hline Sexual harassment policy & Effect & Sum of Squares & Degrees of Freedom & Mean Square & $F$ & $p$ \\
\hline \multirow[t]{3}{*}{ Existence of sexual harassment policy } & Between Groups & 0.69 & 3 & 0.23 & 0.30 & 0.82 \\
\hline & Within Groups & 112.01 & 147 & 0.76 & - & - \\
\hline & Total & 112.70 & 150 & - & - & - \\
\hline \multirow[t]{3}{*}{ Knowledge of sexual harassment policy } & Between Groups & 7.49 & 3 & 2.49 & 7.10 & 0.00 \\
\hline & Within Groups & 52.39 & 149 & 0.35 & - & - \\
\hline & Total & 59.87 & 152 & - & - & - \\
\hline \multirow[t]{3}{*}{ Effectiveness of sexual harassment policy } & Between Groups & 2.12 & 3 & 0.71 & 2.24 & 0.09 \\
\hline & Within Groups & 47.81 & 151 & 0.32 & - & - \\
\hline & Total & 49.93 & 154 & - & - & - \\
\hline
\end{tabular}

$F$, indicates the test statistic of difference and is compared with the critical value of $F$ to determine its significance $p$. 
its application. Concerted efforts by management and/or the parties responsible for the implementation of the SHP to increase the possession rate and training interventions drastically contributes to the overall effectiveness of the policy (Ramsaroop \& Brijball Parumasur, 2007; Retief, 2000). This contributes to the reduction of the incidence of harassment amongst staff, students or clients on campuses (Whatley \& Wasieleski, 2001). Regular evaluation of the effectiveness of the policy is required to ensure that complacency does not erode its value. In this regard it is crucial that higher education institutions collect and maintain statistics on the prevalence of sexual harassment on their campuses. Gouws and Kritzinger (2007) found a lack of serious involvement with the SHP and its implementation by line managers who had also never received training and, subsequently, did not have the necessary skills to deal with complaints of sexual harassment. The low frequency of respondents who were in possession of and who had received training on the SHP suggests that their findings are valid.

Academic staff members who are aware of their rights when reporting an incident of sexual harassment also feel that the policy protects them against retaliation from alleged harassers and, therefore, regard the policy as an effective tool for reducing the incidence of sexual harassment at their workplaces, as indicated by the significant correlations between these criteria for effectiveness. The relatively high number of staff members who are aware of their rights in relation to the absence of training suggests that academic staff members are generally well informed of their human and labour rights. This is understandable in the light of the characteristics of this group and their high level of academic qualifications.

\section{Limitations of the study}

The results of this study may be limited by the low response rate of $22.8 \%$. Other studies also reported relatively low rates of 32\% - 39\% (Green \& Retief, 2001; Pryor, Giedd \& Willeams, 1995; Timmerman \& Bajema, 2000). The sensitive and personal nature of the information that respondents were required to provide may explain their reluctance to participate in the study. It is also possible that the questionnaire reminded certain potential participants of specific incidents of sexual harassment and the negative experience may have prevented them from completing it. The possibility that those employees who are really threatened by sexual harassment did not complete the questionnaires cannot be excluded. Their contributions could have influenced the findings of this study. The study is also limited in its comparability, as no other study that the researcher is aware of has attempted to determine the awareness of sexual harassment policies amongst academic staff at higher education institutions in South Africa. Existing research focused on the public service (Brand \& Silberman, 2002; Du Plessis, 2001; Van der Berg, 2002) and the South African Police Service (Retief, 2000).

Numerous studies have investigated the incidence of sexual harassment on campuses, including harassment of students by students and by academic and other staff (Barak, Fisher, \& Houston, 2006; Gouws \& Kritzinger, 2007; Larocca \& Kromrey, 1999; O'Hare \& O’Donohue, 1998; Ramsaroop \& Brijball Parumasur, 2007; Richman, Rospenda, Nawyn, Flaherty, Fendrich, Drum, \& Johnson, 1999). Students were excluded from this study, as they are not involved in an employment relationship.

A further limitation of the study is the isolation within which the results were interpreted. Limited research exists on academic staff members' awareness of sexual harassment policies and their perceptions of the effectiveness of these policies. This makes it difficult to place the data on the awareness of sexual harassment policies in perspective. The possibility that respondents applied different subjective definitions of sexual harassment when they completed the questionnaire cannot be ignored. Providing no definition was a deliberate action undertaken in an effort not to guide or lead respondents. Interviews with respondents might have provided the researcher with insight into the possible reasons why academic staff is generally not aware of sexual harassment policies at their institutions. Interviews with role-players at higher education institutions responsible for the implementation of policies such as women's forums, human resource practitioners and deans of faculties could have supplemented the quantitative study. This would have increased the validity of this study. The study also did not accommodate cultural variables. In a multi-cultural society like South Africa, this may be regarded as a limitation and it is recommended that research be conducted into the effect of different cultural backgrounds on the perception of sexual harassment.

The results of this study indicate that policies do exist but that the implementation thereof is not effective. This has serious implications for the management of human resources at higher education institutions specifically and all employers in general.

\section{Recommendations}

It is recommended that management of higher education institutions and human resource managers in general take cognisance of this and implement measures to correct the situation and to protect themselves against expensive claims for vicarious liability. More specifically, it is recommended that higher education institutions:

- Conduct an organisational audit or climate survey to determine the prevalence of sexual harassment in their institutions.

- Actively disseminate and promote their policy on sexual harassment in order to increase its visibility and the awareness levels amongst academic staff. An awareness campaign, similar to campaigns that aim to educate about the spreading and prevention of HIV/AIDS, should be launched on campuses to act as a deterrent to cases of sexual harassment. 
- Appoint senior managers, representing both sexes, to take responsibility for the implementation of sexual harassment policies.

- Provide regular training sessions for staff on the contents of the policy, examples of sexual harassment, procedures for lodging complaints and the rights of both harassers and the harassed.

- Issue a clear 'no tolerance' statement and stress the protection of complainants against retaliation and victimisation. This statement must be supported by clearly stating the range of disciplinary sanctions applicable to employees found guilty of sexual harassment. Organisations are advised to clearly communicate that it is a disciplinary offence to victimise or retaliate against an employee who lodges a sexual harassment grievance in good faith.

- Regularly update their policies through consultation with employees, their representatives and consultants. Benchmarking of policies with other higher education institutions is also recommended.

- Preventing sexual harassment is the most effective way of dealing with the problem. Assertiveness and diversity training, together with an effective employment equity programme and a positive corporate culture in which management leads by example will add to the efforts to prevent and successfully manage the prevalence of sexual harassment. Training should also focus on the promotion of professional conduct in the workplace, especially by supervisors. This can be achieved by clearly stating what is regarded as acceptable and unacceptable social behaviour. Sexist attitudes and beliefs are difficult to change as they are formed by an individual's belief and value system. These beliefs should be respected but management should make it clear that acting on these beliefs is not acceptable and contrary to the laws of the country and the policies of the institution. A similar policy statement needs to be made about different cultural roles of males and females which might lead to harassing behaviour.

This study is the first attempt at evaluating the effectiveness of SHP in South Africa and can be regarded as a benchmark study. The results can be improved by a larger sample and a higher response rate. It is recommended that research is conducted to shed more light on the effectiveness of measures to combat sexual harassment in the workplace in general. Research is required to explain the effect of culture, organisational climate and personality factors on the incidence of sexual harassment and on the effectiveness of SHP. New methods to determine the incidence and effective management of sexual harassment need to be explored by future research.

\section{References}

Aalberts, R.J., \& Seideman, L.H. (1996). Sexual harassment policies for the workplace. Cornell Hotel and Restaurant Administration Quarterly, 37(5), 78-85. doi:10.1016/0010-8804(96)88978-6, doi:10.1177/001088049603700527

Anon (2004). Damages for sexual harassment: When employers are liable. Employment Law, 20(1), 3-6.
Barak, A., Fisher, W.A., \& Houston, S. (2006). Individual difference correlates of the experience of sexual harassment among female university students. Journal of Applied Social Psychology, 22, 17-37. doi:10.1111/j.1559-1816.1992.tb01519.x

Bennett, J. (2002). Southern African higher educational institutions challenging sexual violence, sexual harassment: A handbook of resources. Cape Town: African Gender Institute, University of Cape Town.

Bless, C., \& Higson-Smith, C. (2004). Fundamentals of social research methods: An African perspective ( 3 rd ed.). Lansdowne: Juta.

Brand, H.E., \& Silberman, M.T. (2002). Perceptions of sexual discrimination, sexual harassment and job satisfaction among female employees in the public sector. South African Journal of Economic and Management Sciences, 5, 607-624.

Caudron, S. (1995). Sexual politics. Personnel Journal, 17(5), 50-61.

Corr, P.J., \& Jackson, C.J. (2001). Dimensions of perceived sexual harassment: effects of gender and status/liking of protagonist. Personality and Individual Differences, 30, 525-539. doi:10.1016/S0191-8869(00)00052-0

Dillon, W.R., Madden, T.J., \& Firtle, N.H. (1990). Marketing research in a marketing environment (2nd ed.). Homewood, IL: Irwin.

Doane, D.P., \& Seward, L.E. (2007) Applied statistics for business and economics (2nd ed.). New York: McGraw-Hill.

Du Plessis, J.A. (2001). Die voorkoms van seksuele teistering in die staatsdiens. Unpublished master's thesis, Stellenbosch University, Stellenbosch.

Finnemore, M., \& Van Rensburg, R. (2002). Contemporary labour relations (2nd ed.). Durban: LexisNexis Butterworths.

Gouws, A., \& Kritzinger, A. (2007). Dealing with sexual harassment at institutions of higher learning: Policy implementation at a South African university. South African Journal of Higher Education, 21(1), 68-84.

Green. S., \& Retief, R. (2001). Sexual harassment in the SAPS. Servamus, 94(11), 44-50.

Grobler, P.A., Erasmus, B.J., \& Kölkenbeck-Ruh, R.K. (2003). A model for the management of sexual harassment in South African companies. Management Dynamics, 12(1), 36-46.

Grogan, J. (2004). Vicarious harassment: Employers become reluctant insurers. Employment Law, 20(4), 3-10.

Hayter, S. (1996). Workplace harassment: A conflict management systems approach. South African Labour Bulletin, 20(5), 55-57.

Kastl, M.A., \& Kleiner, B.H. (2001). New developments concerning discrimination and harassment in universities. International Journal of Sociology and Social Policy 21(8), 156-164. doi:10.1108/01443330110789916

Laabs, J.J. (1998). What you're liable for now. Workforce, 77(10), 34-40.

Larocca, M.A., \& Kromrey, J.D. (1999). The perception of sexual harassment in higher education: Impact of gender and attractiveness. Sex Roles, 40, 921-940. doi:10.1023/A:1018829222894

Licata, B.J., \& Popovich, P.M. (1987). Preventing sexual harassment: A proactive approach. Training and Development Journal, 41(5), 34-38.

Maree, K. (2007). First steps in research. Pretoria: Van Schaik.

Moore, H.L., Gatlin-Watts, R.W., \& Cangelosi, J. (1998). Eight steps to a sexual harassment-free workplace. Training and Development, 52(4), 12-14.

Mouton, J. (1996). Understanding social research. Pretoria: Van Schaik.

O'Hare, E.A., \& O'Donohue, W. (1998). Sexual harassment: Identifying risk factors. Archives of Sexual Behaviour, 27, 561-580. doi:10.1023/A:1018769016832, PMid:9883305

Orlov, D., \& Roumell, M. T. 1999. What every manager needs to know about sexual harassment. New York: McGraw-Hill.

Owens, M.G., Gomes, G.M., \& Morgan, J.F. (2004). Sexual harassment in the European Union: The dawning of a new era. SAM Advanced Management Journal, 69(1), 4-11.

Paludi, M.A. (1996). Sexual harassment on college campuses: Abusing the ivory tower. Albany: State University of New York Press.

Pearce, J.A., \& DiLullo, S.A. (2001). A business policy statement model for eliminating sexual harassment and related employer liability. SAM Advanced Management Journal, 66(2), 12-21.

Peirce, E.R., Rosen, B., \& Hiller, T.B. (1997). Breaking the silence: Creating user-friendly sexual harassment policies. Employee Responsibilities and Rights Journal, 10 225-242. doi:10.1023/A:1025643318386

Pryor, J.B., Giedd, J.L., \& Willeams, K.B. (1995). A social psychological model for predicting sexual harassment. Journal of Social Issues, 51, 69-84. doi:10.1111/j.1540-4560.1995.tb01309.x

Ramsaroop, A., \& Brijball Parumasur, S. (2007). The prevalence and nature of sexual harassment in the workplace: A model for early identification and effective harassment in the workplace: A model for early identification and effective
management thereof. SA Journal of Industrial Psychology/SA Tydskrif vir management thereof. SA Jour
Bedryfsielkunde, 33(2), 25-33.

Retief, R.T. (2000). Guidelines for the handling of sexual harassment in the South African Police Service. Unpublished master's dissertation, University of Stellenbosch, Stellenbosch.

Richman, J. A., Rospenda, K.M., Nawyn, S.I., Flaherty, J.A., Fendrich, M., Drum, M.L., \& Johnson, T.P. (1999). Sexual harassment and generalized workplace abuse among university employees: prevalence and mental health correlates. American Journal of Public Health, 89, 358-363. doi:10.2105/AJPH.89.3.358, PMid:10076485, PMCid:1508597

Rowe, M. (1996). Dealing with harassment: A systems approach. In M.S. Stockdale (ed). Sexual harassment in the workplace: perspectives, frontiers, and response strategies. Thousand Oaks, CA: Sage. 
Rycroft, A., Le Roux, R., \& Orleyn, T. (2005). Sexual harassment in the workplace: Law, policies and processes. Durban: LexisNexis Butterworths.

Sarantakos, S. (2006). Social research. Hampshire: Palgrave.

South Africa. (1995). Labour Relations Act (no. 66 of 1995). 2005 Amended Code of Good Practice on the Handling of Sexual Harassment Cases in the Workplace. Pretoria: Government Printers.

South Africa. (1998). Employment Equity Act (no. 55 of 1998). Pretoria: Government Printers.

SPSS Inc. (2007). SPSS 15.0 for Windows. Chicago, IL: SPSS Incorporated.

Stockdale, M.S. (1996). Sexual harassment in the workplace: Perspectives, frontiers and response strategies. Thousand Oaks, CA: Sage Publications.
Timmerman, G., \& Bajema, C. (2000). The impact of organisational culture on perceptions and experiences of sexual harassment. Journal of Vocationa perceptions and $188-205$. doi:10.1006/jvbe.1999.1741

Van der Berg, J.P. (2002). The perceptions of employees regarding sexual harassment at a busuness unit of a public utility. Unpublished master's dissertation, Rand Afrikaans University, Johannesburg.

Whatley, M.A., \& Wasieleski, D.T. (2001). The incidence of sexual harassment in Academia: A pilot study. Radical Pedagogy. Retrieved March 12, 2010 from http:// radicalpedagogy.icaap.org/content/issue

Wilken, E.C., \& Badenhorst, J.W. (2003). A comparative analysis of sexual harassment policies at selected higher education institutions in South Africa. South African Journal of Higher Education, 17, 197-205. 